\title{
Discussion on Equipment Virtual Archives of Art Colleges
}

\author{
Yali Li \\ Sichuan Conservatory of Music, Chengdu, 610021, China
}

\begin{abstract}
Keywords: art colleges; equipment; virtual archive
\end{abstract}
\begin{abstract}
This paper starts from development status of equipment archive management of art colleges and reason analysis and takes theoretical knowledge of equipment virtual archive management as basis to discuss the feasibility and necessity of establishing equipment virtual archive of art colleges, and then proposes the specific scheme for construction of equipment virtual archive of art colleges and the problems we shall pay attention to for the purpose of realizing scientific archive management through electronic computer network technology, thus exerting the due value of equipment archive in scientific research, teaching, and technical service of art colleges to maximum degree.
\end{abstract}

\section{Overview of virtual archive}

The virtual archive will be the senior form of archive development. The virtual archive can be called an orderly information system or an orderly information space rather than an entity institution. Through network technology, it adopts digital technology to store the information so as to make the archival information scattered in different areas connected together through electronic communication systems. Besides, the equipment virtual is neither equal to archive database of general meaning, nor equal to the archives of traditional significance; the archive content is not limited to video tape, optical disk, magnetic disk, paper document and other real objects, and abandons the drawback of traditional archives in which people need to make manual inquiry and only the content can be inquired, but the specific content can't be inquired for archive database. Through data collection means such as scanning, the equipment virtual archive can digitize and electronize the archives, thus we can make inquiry via database retrieval and directly obtain the content of required archives.

\section{Reason analysis on problems existing in management of equipment archives of art colleges at present}

(I) The low efficiency of traditional equipment archive management has been unable to meet great utilization demand of equipment archives.

As for art colleges, in view of the special property of profession, the technology generally changes quickly. Therefore, there is a high frequency for art colleges to use large-scale precise instruments and firmware devices, and those equipments also have a high updating rate. However, the installation and debugging of those new equipments need a commissioning stage, and the operating instructions for attached software and new equipment need guidance of relevant materials, all of which make the popularization of new equipments in art colleges obstructed, thus the art colleges have to continue to use traditional way to manage archives. However, the traditional way is to place equipment archives into archives, thus directly influencing the perfectness rate of archiving and then resulting in imbalance between supply and demand. Therefore, the low efficiency of traditional equipment archive management has been unable to meet great utilization demand of equipment archives.

(II) The traditional equipment archive management doesn't meet the development demand of modern management of equipment.

As for art colleges, the difficult point of archive establishment mainly lies at specific management departments. Generally, the teaching apparatus used by science and engineering colleges are fixed in one research institution or laboratory; however, the teaching apparatus used by art colleges are characterized by large mobility, etc., such as camera used in film and television art 
and advanced camera used in photography; in the process of establishment of operation and maintenance archives for above apparatus, there is a great space spanning; in case of damage and compensation, it is required to inquire relevant use record; in case of maintenance, it is required to inquire the relevant equipment installation materials and specification. Besides, the on-spot record is required, and the original artificial inquiry shall be adopted. In this way, the manual record must take large quantity of time and labor force, thus the perfectness of successive collection and archiving of archives will be influenced and the equipment management personnel's work burden will be increased. Therefore, the traditional equipment archive management doesn't meet or fit to the development demand of modern management of equipment.

\section{Feasibility and necessity of establishing equipment virtual archive of art colleges}

(I) By virtue of unique information processing speed of virtual archive, it is able to provide reliable information for equipment management while the establishment of equipment archives is quickened.

One of the reasons why the traditional equipment archives cause scattered information space, difficult transfer, low efficient archive establishment, and slow establishment speed is manual operation. As is known to us, the establishment of equipment archive is a long process; the equipment information produced in various links of equipment management and use can be timely archived to provide true, time and reliable use information of equipment for management user in next link so as to realize a virtuous circle of establishment of equipment archives, especially for frequent mobility and high utilization rate of equipments of art colleges. By virtue of equipment virtual archive, it is able to suitably solve those problems, thus greatly reducing difficulty in equipment management of art colleges.

(II) By virtue of unique information processing way of virtual archive, it is good for improving the utilization ratio of equipment archives.

By virtue of unique information processing way of equipment virtual archives, it is able to not only realize resource sharing of original archives, and make authorized inquirers carry out operation through network access within certain range, but also realize the transfer from single user to multiple users. Besides, if it is able to obtain the reasonable allocation of asset management department and realize resource sharing of college apparatus to maximum degree, it will be possible to realize the preservation and appreciation of important assets. This quick information processing way thoroughly abandons the drawback of traditional archive in which there is only one copy of original archive which can be only provided for single user, thus greatly improving the imbalance between supply and demand.

(III) By virtue of unique storage medium of virtual archive, it is able to both make use of limited resources to expand storage ability, and greatly save storage space.

As for art colleges, the virtual archive reduces establishment difficulty of equipment archives and makes large quantity of valuable equipment information able to be effectively and timely processed, thus it is able to ensure that the equipment archive is complete and true and greatly meet retrieval demand of archive information inquirers. What's more, the equipment virtual archive can easily complete the electronic data, audio and video document, picture files and other information which can't be completely archived through traditional archive way. Therefore, by virtue of unique storage medium of virtual archive, it is able to both make use of limited resources to expand storage ability, and greatly save storage space.

(IV) By virtue of unique inquiry mode of virtual archive, it is able to improve the perfectness ratio of equipment archives while the high-speed retrieval and inquiry efficiency is ensured.

Compared to traditional archive in which the original archive is called to complete the whole inquiry process after manual inquiry on file list, the equipment virtual archives realize the retrieval through non-contact archives. In short, it is unnecessary for inquirers to transfer original archives and the inquirers are not limited by time and territory; in this way, it is able to not only reduce 
archive managers' workload and let them put limited energy into management work, but also effectively avoid the deficiency after borrowing, thus greatly improving the perfectness ratio of equipment archives. The virtual archive has strong retrieval function, thus it can provide inquirers with convenience and save large quantity of time.

(V) By virtue of unique utilization technology of virtual archive, it is able to greatly improve the information management ability of equipment archives.

The equipment virtual archive is operated through unique storage medium. In other words, the equipment archive is digitized and electronized through a set of data storage unit, and it is unnecessary to input other apparatus, which not only greatly saves precious storage space, but also reduces archive keeping expenditure to certain degree, thus saving archive keeping cost. This is entirely different from the situation that the traditional archive needs certain archive shelf, special house, and heat and moisture preservation apparatus, etc.

\section{Design procedure for equipment virtual archives of art colleges}

\section{(I) Archive collection system}

The multimedia archive content is collected through video capture system, audio capture system, and photographic film scanner, and the archive collection system which serves for archives generally has daily processing functions such as archive entering, document-level entering, file-level entering, and file management. The process from application for equipment procurement to equipment's being put into daily use is undertaken by procurement, acceptance, use, and maintenance department to enter and classify scientific research archives, teaching archives, service archives, and management archives of equipment respectively; then, through computer network, it is able to make archive classification department able to effectively, timely, and accurately summarize the archives for convenience of use of departments of next link.

(II) Archive inquiry system

On one hand, through database management, the inquiry system has many inquiry means; furthermore, the system has good retrieval ability through which it is able to provide multi-conditional combination inquiry according to retrieval item, optimize common retrieval means, and provide video and audio inquiry service; besides, the scattered archives can be connected together through network technology, and the users can establish connection with archive information center through network. On the other hand, through archive management department, it is able to directly realize the inquiry without geological position and time limitations. Finally, through internet, the inquirers can carry out remote looking-up for archive resources; after completion of inquiry, they can carry out downloading and calling according to actual demand. The abovementioned three systems are mutually cooperated and none is dispensable.

(III) Archive management system

The equipment virtual archive system consists of system maintenance and management, file management, information management, and other main functions, through which the setting of archive management authority, classification and arrangement of files, and daily maintenance on database are realized.

\section{Problems which we shall pay attention to in the process of establishing equipment virtual archive of art colleges}

(I) To suitably and timely adjust archive management system

In the process of construction of virtual archives, it is required to carry out necessary and timely adjustment for current archives management system of art colleges, gradually break segment condition based on the principle of "uniform management and efficiency improvement", make an overall planning, and finally establish scientific network management system by stage. Meanwhile, while we organize the construction of virtual archives, we still shall pay attention to connection 
with foreign network so as to realize archive information resource sharing within large scope.

(II) To quicken the application of modern technology in archive management

Some special problems shall be solved in the construction and operation process of virtual archives; after all, the virtual archives have higher requirement for information processing technology. The virtual archive not only has strict requirement for its safe confidentiality, but also has high requirement for primitiveness and authenticity of digital archive information as well as limitations for its service object; not all people can utilize the archive information. Therefore, it is required to develop and apply a series of new technology such as identity cognizance, intelligent retrieval, information hiding, digital watermarking, electronic seal, operation tracking, and information encryption.

(III) The construction of virtual archive shall be a progressive process.

There exists a transition period from traditional archives to virtual archives. The construction of virtual archives of art colleges must be done by step and stage, and it is required to gradually realize the transition from entity archives (keeping traditional entity archives) to "virtual-real" archives, and finally establish distributed virtual archives. The sweeping approach is impossible. We must have a clear knowledge of construction process of virtual archives so as to keep a foothold on reality, lay a good foundation, get hold of development and reform direction of archives, quicken the talent training, and formulate development strategy planning.

(IV) To establish a high-quality archives management personnel team

Chinese archives personnel's modern science and technology knowledge is insufficient and their awareness of modern technology and network is very weak; however, the construction of virtual archives proposes higher requirement and challenge for relevant professional personnel and the traditional archives management means have been unable to meet the modern construction requirement. Therefore, the art colleges shall regard personnel training as the most important infrastructure and pay more attention to cultivation of relevant personnel than any other time. On one hand, it is required to create a composite and high-quality team which can adapt to the archive development demand as soon as possible, enhance business and science \& technology knowledge training on current personnel, and adjust personnel structure; on the other hand, it is required to attract a batch of professional personnel with modern science and technology knowledge to provide powerful and fundamental talent support for construction of virtual archives.

(V) To greatly promote standardization process of archives work

The construction of virtual archives proposes new requirements for standardization process of archives work. As the operation center of archives information, the virtual archives under network carry out centralized control on archive information source scattered in different place. The most remarkable feature of virtual archives is the comprehensive application of information technology, and the application of information technology can't be separated from scientific and standard establishment of various standards. Therefore, it is required to greatly promote standardization process of archive management, and carefully formulate, perfect, and execute the uniform principles and standards with respect to archives-related work, technology, and equipment as soon as possible.

\section{Conclusion:}

In conclusion, with rapid development of network technology and information technology, the creation of equipment virtual archives meets the development demand of modern equipment management of art colleges, and also exerts various functions of equipment archives to maximum degree, so as to provide more advantageous services for teaching reform, education management, social service, and scientific research of art colleges. Currently, the campus network construction of China's art colleges is relatively perfect, and the office automation is relatively popular. Therefore, the creation of equipment virtual archives of art colleges has advantageous conditions both in hardware and software, thus realizing more humanized, efficient, scientific, and reasonable archives management of art colleges. 


\section{References:}

[1] Zhang Qun: Reasonable Application of College Archives under Modern New Technical Condition and Conception on Archiving Management [J], Journal of Xinjiang Medical University, 2009

[2] Chang Cheng: Management and Application of College Archives in Information Age [J], Science \& Technology Information, 2009

[3] Lu Qinglan: Discussion on Apparatus Archives Management of Colleges [J], Lantai World, 2009

[4] Wang Yan: Information-based Management on Apparatus Archives of Colleges [J], Journal of Xianning College, 2005

[5] Pang Li, Zhao Haomai: Preliminary Exploration on Centralized Archives Management Mode of Colleges under Background of Electronic Documents [J], Lantai World, 2011

[6] Li Limin: Discussion on Archives Work Mode of Junior Colleges in Electronic Age [J], Inside and Outside Lantai, 2009

[7] Yang Hongyan: Exploration and Analysis on Scientific Management of Electronic Documents of Colleges [J], Science and Technology Archives, 2009

[8] Li Yuhuan: Archives Management of Colleges under Condition of Paperless Office [J], Lantai World, 2006 